\title{
Morpho-physiological parameters of wheat cultivar for cultivation on aluminum-acid soils
}

\author{
Lyudmila Volkova, Oksana Amunova, and Eugene Lisitsyn* \\ Federal Agricultural Research Center of the North-East named N.V. Rudnitsky, Kirov, Russian \\ Federation
}

\begin{abstract}
One way to combine the requirement of organic farming and the requirement to increase grain production is to create genotypes with resistance to abiotic stressors. The aim of the work is to adjust the parameters of the existing model of spring wheat cultivar for cultivation on natural aluminum-acid soil. The stress conditions of the aluminum-acid soil led to decrease in the yield of 19 wheat cultivars by an average of $72.5 \%$ compared to neutral soil. The yield level was statistically significantly correlated with such elements of the yield structure as the 1000 -grain mass $(r=0.76)$, the mass of grains per main spike $(r=0.92)$, and per plant $(\mathrm{r}=0.88)$. Resistant cultivars reduced the content of chlorophylls in leaves by $29-43 \%$, sensitive ones - by almost three times. The content of carotenoids in sensitive cultivars decreased by $58 \%$; in resistant cultivars the content of carotenoids was within control, or slightly decreased. Under conditions of aluminum-acid soil, a close relationship ( $\mathrm{r}$ $=0.62)$ was revealed between the wheat yield and the proportion of chlorophyll in the light-harvesting complexes of flag leaf chloroplasts. The corrected target morpho-physiological indices of plants of spring soft wheat are given, which are most optimal when growing on aluminum-acid sod-podzolic soils
\end{abstract}

\section{Introduction}

Wheat (Triticum aestivum L.) is the third most important food crop after corn and rice. It is the world's most cultivated crop [1]. In order to provide food for the rapidly growing population of the Earth, wheat production should increase by at least $50 \%$ by 2030 [2]. Of course, such a requirement conflicts with the concept of "organic farming" introduced in developed countries, since the main economic goal of organic farming is to combat overproduction of crop products. Therefore, marginal plots of land can be used for organic farming, but they are most often characterized by the presence of certain stressors. As one way of combining the requirement of organic farming and the requirement of increasing grain production, it is possible to recommend the creation and cultivation of genotypes with resistance to abiotic stressors. Such genotypes can be created by identifying and/or selecting agronomic and physiological traits that characterize stress resistance and have an

\footnotetext{
* Corresponding author: edaphic@mail.ru
} 
effect on the crop yield value [3-5]. Thus, there is a need for breeding based on different morpho-physiological parameters in order to further increasing wheat grain production [6].

The resistance of plants to various types of abiotic stressors (high or low air temperature, excess salts, moisture and increased metal concentrations) has attracted increasing attention in recent decades by geneticists and breeders, since these factors lead to a decrease in the productivity of basic crops (cereals, legumes, forages) worldwide by an average of more than $50 \%$. The effectiveness of modern molecular breeding methods is still relatively low despite significant progress in gene identification and QTLs, to varying degrees related to plant resistance to abiotic stresses. The causes of this phenomenon are considered in the special breeding and genetic literature, although the polygenic nature of resistance to any abiotic factor can be indicated as the main reason. At the same time, the effectiveness of using traditional physiological and morphological parameters reflecting the integral response of the plant to stressful impact is not questioned by anyone. In this regard, it is necessary to expand the use of such parameters by studying the response of plants to specific types and levels of stressors or their combination. The effectiveness of the selection of desired genotypes largely depends on how accurately the breeder imagines the result of work - the ideal combination of plant features expressed in the form of a cultivar model.

For the conditions of the North-East of the Non-Chernozem Zone of the Russian Federation, models of cultivars of main grain crops have been developed: spring barley [7], wheat [8], and oats [9]. First, however, different authors use different parameters to describe the cultivars model; secondly, these models are designed for breeding purposes (to determine the direction of breeding development); thirdly, they are offered for cultivation under optimal soil and agricultural conditions.

The aim of the work: to adjust the available models of spring wheat cultivars for cultivation on natural aluminum-acid sod-podzolic soil.

\section{Material and methods}

Data from field studies 2015-2019 on natural aluminum-acid (16 mg of exchangeable aluminum per $100 \mathrm{~g}$ of soil at $\mathrm{pH}$ 3.8) sod-podzolic soil (Kirov region, Russian Federation). Nineteen cultivars of spring soft wheat from the world collection of VIR and the working collection of the laboratory of wheat breeding of FARC of the North-East were used as the object of research (tab. 1). As a standard cultivar, the cv. Svecha bred in FARC of the North-East was used, which in 2005 was included in the State Register of Breeding Achievements of the Russian Federation for the Northern and Volga-Vyatka Regions of the Russian Federation. This variety is characterized by early ripeness, stable yield, and resistance to increased acidity of the soil and drought.

Field accounts and observations were performed according to [10]. The development of the elements of the yield structure was estimated by 30 plants in three times repetition for each cultivar. In the flowering stage, the total number of leaves was calculated, their length and width were determined using a ruler; then the total leaf area and the area of one leaf were calculated. Before harvesting, growth parameters (height of plants, length of spike) were evaluated; head-bearing shoots, number of grains per main ear and per plant were calculated. After harvesting, the yield was determined by weight and the 1000-grain mass was calculated.

Under laboratory conditions, the state of the pigment complex of flag leaves was evaluated (the content of chlorophylls $a$ and $b$, carotenoids, their weight ratios and the proportion of chlorophylls in LHC = light-harvesting complexes of photosystems). According to procedure [11], pigments were extracted with $100 \%$ acetone and then their concentration was determined spectrophotometrically (UVmini-1240, Shimadzu Corporation, Japan) and the content was calculated on a basis of $1 \mathrm{mg}$ of dry leaf matter. 
The software StatSoft Statistica 10 (analysis of variances and correlation analysis) was used for statistical processing of the obtained data. Table 2-4 shows the arithmetic mean values and their standard error. The significance of differences between variants was assessed at $\mathrm{p} \leq 0.05$.

\section{Results and discussion}

A comparison of the yield of the studied cultivars when cultivated on natural aluminumacid and limed neutral ( $\mathrm{pH}$ 6.8, absence of exchangeable aluminum ions) soils of the experimental site confirmed the presence of a strong stress factor: the minimum decrease in yield was 46 (cv. Duet Chernozemiya), the maximum - 99\% (cv. AC Taber). For all the cultivar tested, significant depressions of the yield characteristics of both the main and lateral stems are shown (tab. 1).

Table 1. Relative (aluminum-acid soil / neutral soil) yield characteristics of the studied wheat cultivars.

\begin{tabular}{|l|c|c|c|c|}
\hline \multirow{2}{*}{ Cultivar } & \multicolumn{3}{|c|}{ Grain mass } & \multirow{2}{*}{ Yield capacity } \\
\cline { 2 - 4 } & Per main ear & Per plant & 1000 -grain & 0.54 \\
\hline Svecha - standard & 0.46 & 0.27 & $0.94^{*}$ & 0.43 \\
\hline Duet Chernozemiya & 0.39 & 0.25 & 0.85 & 0.42 \\
\hline Tulaikovskaya 105 & 0.55 & 0.47 & $0.98^{*}$ & 0.34 \\
\hline Estivum 155 & 0.57 & 0.37 & 0.84 & 0.33 \\
\hline Olga & 0.39 & 0.28 & 0.80 & 0.33 \\
\hline Omskaya 39 & 0.45 & 0.30 & 0.74 & 0.26 \\
\hline Biryusa & 0.25 & 0.14 & 0.74 & 0.26 \\
\hline Magistral'naya 1 & 0.40 & 0.30 & 0.80 & 0.23 \\
\hline Aktyube 19 & 0.14 & 0.13 & 0.70 & 0.20 \\
\hline Bashkirskaya 28 & 0.31 & 0.22 & 0.77 & 0.17 \\
\hline Legenda & 0.43 & 0.38 & $0.99^{*}$ & 0.16 \\
\hline Line 3691 h & 0.30 & 0.28 & 0.82 & 0.14 \\
\hline Kinel'skaya otrada & 0.15 & 0.07 & 0.72 & 0.14 \\
\hline Lutescence 30 & 0.24 & 0.22 & 0.82 & 0.08 \\
\hline Tyumenskaya 80 & 0.28 & 0.25 & 0.83 & 0.06 \\
\hline Altaiskaya 80 & 0.18 & 0.16 & 0.81 & 0.06 \\
\hline Nawra & 0.23 & 0.18 & $0.96^{*}$ & 0.02 \\
\hline Karabalykskaya 98 & 0.20 & 0.16 & 0.80 & 0.01 \\
\hline AC Taber & 0.13 & 0.11 & 0.62 & \\
\hline
\end{tabular}

Note: * - statistically significant difference from control values $(p \leq 0.05)$ is absent

In cv. Tulaikovskaya 105 and Legenda, evaluated in preliminary laboratory experiments [12] as resistant to aluminum action, the depression of grain mass per main spike was lower or at the level of the standard cv. Svecha $(45,53$ and $54 \%$, respectively), grain mass per plant - significantly less than the standard $(57,62$ and $73 \%)$.

$\mathrm{Cv}$. Estivum 155 stood out from the group of aluminum ions-sensitive varieties - the mass of the grain per main ear under conditions of aluminum acid stress decreased by $43 \%$, the mass of grain per plant - by $63 \%$. A $16 \%$ decrease in the 1000 -grain mass in this cultivar partially provoked a loss of yield compared to the cv. Legenda, Tulaikovskaya 105 and Svecha, in which the index 1000-grain mass on aluminum acid soil was insignificantly different from the control value.

The studied cultivars differed in terms of what structural elements retained productivity. The stress-resistant cv. Tulaikovskaya 105 retained the size of the seeds (parameter 1000grain mass) but at the same time reduced the total weight of the grain both in the main and lateral ears. The second resistant cultivar - Duet Chernozemiya - had a high productivity of ears and, in addition, the preservation of plants in hard conditions of abiotic stress. 
However, focusing on the absolute indicators of the yield capacity of the studied genotypes on an aluminum-acid background, one can distinguish several cultivars that exceed the standard cultivar or are at the same yield level as it (tab. 2): Omskaya 39, Duet Chernozemiya, Olga, Tulaikovskaya 105, and Estivum 155.

Table 2. Development of productivity elements of tested wheat varieties on aluminum acid soil (average for 2014-2019).

\begin{tabular}{|c|c|c|c|c|}
\hline \multirow{2}{*}{ Cultivar } & \multicolumn{3}{|c|}{ Grain mass, $\mathrm{g}$} & \multirow{2}{*}{ Yield capacity, $\mathrm{g} / \mathrm{m}^{2}$} \\
\hline & Per main ear & Per plant & 1000-grain & \\
\hline Svecha - standard & $0.73 \pm 0.11$ & $0.80 \pm 0.13$ & $36.31 \pm 0.79$ & $159.0 \pm 16.3$ \\
\hline Omskaya 39 & $0.84 \pm 0.15$ & $0.88 \pm 0.18$ & $32.63 \pm 2.01$ & $190.4 \pm 13.6$ \\
\hline Duet Chernozemiya & $0.56 \pm 0.04$ & $0.66 \pm 0.06$ & $35.43 \pm 1.45$ & $161.5 \pm 16.3$ \\
\hline Olga & $0.55 \pm 0.04$ & $0.68 \pm 0.06$ & $30.65 \pm 0.32$ & $142.2 \pm 9.3$ \\
\hline Tulaikovskaya 105 & $0.84 \pm 0.04$ & $1.16 \pm 0.35$ & $36.34 \pm 1.57$ & $132.6 \pm 12.5$ \\
\hline Estivum 155 & $0.66 \pm 0.10$ & $0.79 \pm 0.07$ & $32.02 \pm 1.03$ & $131.9 \pm 19.6$ \\
\hline Bashkirskaya 28 & $0.40 \pm 0.01$ & $0.44 \pm 0.01$ & $32.91 \pm 0.91$ & $108.9 \pm 11.8$ \\
\hline Magistral'naya 1 & $0.63 \pm 0.08$ & $0.77 \pm 0.14$ & $35.08 \pm 3.39$ & $104.4 \pm 32.9$ \\
\hline Biryusa & $0.31 \pm 0.04$ & $0.32 \pm 0.04$ & $27.17 \pm 0.83$ & $81.5 \pm 10.4$ \\
\hline Kinel'skaya otrada & $0.23 \pm 0.05$ & $0.23 \pm 0.05$ & $27.10 \pm 0.89$ & $63.0 \pm 9.5$ \\
\hline Line $3691 \mathrm{~h}$ & $0.27 \pm 0.03$ & $0.27 \pm 0.03$ & $26.77 \pm 1.56$ & $35.2 \pm 6.7$ \\
\hline Legenda & $0.32 \pm 0.01$ & $0.32 \pm 0.01$ & $28.93 \pm 0.33$ & $33.3 \pm 6.4$ \\
\hline Lutescence 30 & $0.22 \pm 0.03$ & $0.22 \pm 0.03$ & $27.44 \pm 0.98$ & $33.3 \pm 11.1$ \\
\hline Tuymenskaya 80 & $0.24 \pm 0.03$ & $0.24 \pm 0.03$ & $31.02 \pm 0.32$ & $22.2 \pm 3.2$ \\
\hline Altaiskaya 80 & $0.11 \pm 0.01$ & $0.11 \pm 0.01$ & $22.48 \pm 1.20$ & $11.1 \pm 0.6$ \\
\hline Nawra & $0.18 \pm 0.03$ & $0.18 \pm 0.03$ & $30.89 \pm 2.36$ & $7.4 \pm 3.0$ \\
\hline Karabalykskaya 98 & $0.22 \pm 0.00$ & $0.22 \pm 0.00$ & $30.17 \pm 1.14$ & $7.4 \pm 2.3$ \\
\hline Aktyube 19 & $0.12 \pm 0.03$ & $0.12 \pm 0.03$ & $23.92 \pm 0.67$ & $4.4 \pm 2.3$ \\
\hline AC Taber & $0.12 \pm 0.03$ & $0.12 \pm 0.03$ & $21.91 \pm 3.09$ & $2.2 \pm 0.6$ \\
\hline
\end{tabular}

The analysis of plant development of the tested cultivars in the field conditions revealed statistically significant positive paired correlations between plant yields on the one hand and the productivity of the main and lateral ears, as well as the 1000-grain mass on the other hand. Under conditions of the control (neutral) soil site, the values of these correlations were, respectively, $0.84 ; 0.80$ and 0.87 ; under conditions of aluminum acid soil - 0.92; 0.88 and 0.76 .

Aluminum acid stress had a statistically significant effect on the development of the assimilation apparatus of plants of spring soft wheat: the development of leaf surface and the content of photosynthetic pigments in leaves are significantly reduced. Tab. 3 shows the development dynamics of wheat plant leaf apparatus under conditions of aluminum acid soils.

Table 3. Development of leaf apparatus of soft spring wheat plants under conditions of aluminum acid soils.

\begin{tabular}{|l|c|c|c|c|}
\hline \multirow{2}{*}{ Cultivar } & Growth stage & $\begin{array}{c}\text { Total leaf area, } \\
\mathrm{cm}^{2}\end{array}$ & $\begin{array}{c}\text { Number of leaves, } \\
\text { pcs. }\end{array}$ & $\begin{array}{c}\text { Average leaf } \\
\text { area, } \mathrm{cm}^{2}\end{array}$ \\
\hline \multirow{3}{*}{ Legenda } & Booting & $46.52 \pm 3.15$ & $5.2 \pm 0.3$ & $8.95 \pm 0.61$ \\
\cline { 2 - 5 } & Heading & $46.63 \pm 2.96$ & $4.9 \pm 0.2$ & $9.52 \pm 0.58$ \\
\cline { 2 - 5 } & Flowering & $36.34 \pm 3.04$ & $3.6 \pm 0.2$ & $10.09 \pm 0.85$ \\
\hline \multirow{2}{*}{$\begin{array}{l}\text { Estivum } \\
\text { 155 }\end{array}$} & Booting & $51.14 \pm 2.82$ & $4.5 \pm 0.2$ & $11.43 \pm 0.59$ \\
\cline { 2 - 5 } & Heading & $49.61 \pm 3.04$ & $3.7 \pm 0.2$ & $13.57 \pm 0.90$ \\
\hline \multirow{2}{*}{$\begin{array}{l}\text { Estivum } \\
\text { V313 }\end{array}$} & Flowering & $42.59 \pm 2.24$ & $3.0 \pm 0.2$ & $14.30 \pm 0.57$ \\
\cline { 2 - 5 } & Booting & $69.40 \pm 5.06$ & $5.1 \pm 0.2$ & $14.08 \pm 1.50$ \\
\hline \multirow{2}{*}{$\begin{array}{l}\text { Sibirskaya } \\
14\end{array}$} & Heading & $73.31 \pm 7.61$ & $4.3 \pm 0.3$ & $18.54 \pm 2.63$ \\
\cline { 2 - 5 } & Flowering & $60.94 \pm 7.44$ & $3.1 \pm 0.1$ & $19.59 \pm 2.30$ \\
\cline { 2 - 5 } & Booting & $58.64 \pm 6.82$ & $4.7 \pm 0.2$ & $12.72 \pm 1.64$ \\
\hline
\end{tabular}


Severe aluminum acid stress had a significant effect on the state of the pigment complex of flag leaves. As shown in tab. 4, almost all parameters are significantly reduced in stress conditions, with the exception of the mass ratio of chlorophylls $a$ to $b$. An increase in this ratio is characteristic of the effect of any type of stressor [11].

Table 4. The state of the pigment complex of flag leaves of soft spring wheat in the flowering stage.

\begin{tabular}{|c|c|c|c|c|}
\hline \multirow[b]{2}{*}{ Parameter } & \multicolumn{4}{|c|}{ Cultivar } \\
\hline & Legenda & $\begin{array}{c}\text { Magistral'naya } \\
1\end{array}$ & Svecha & Estivum 155 \\
\hline \multirow{2}{*}{$\begin{array}{l}\text { Chlorophyll } a \text { content per } 1 \mathrm{~g} \text { of } \\
\text { dry leaf matter, mg }\end{array}$} & $6.13 \pm 0.22$ & $6.10 \pm 0.17$ & $4.60 \pm 0.17$ & $4.46 \pm 0.15$ \\
\hline & $10.83 \pm 0.09$ & $12.25 \pm 0.44$ & $11.12 \pm 0.45$ & $7.76 \pm 0.26$ \\
\hline \multirow{2}{*}{$\begin{array}{l}\text { Chlorophyll } b \text { content per } 1 \mathrm{~g} \text { of } \\
\text { dry leaf matter, mg }\end{array}$} & $2.89 \pm 0.26$ & $3.12 \pm 0.10$ & $3.01 \pm 0.14$ & $2.32 \pm 0.11$ \\
\hline & $7.13 \pm 0.27$ & $7.58 \pm 0.45$ & $5.96 \pm 0.42$ & $4.35 \pm 0.33$ \\
\hline \multirow{2}{*}{$\begin{array}{l}\text { Carotenoids content per } 1 \mathrm{~g} \text { of } \\
\text { dry leaf matter, mg }\end{array}$} & $2.13 \pm 0.05$ & $2.22 \pm 0.03$ & $1.27 \pm 0.01$ & $1.45 \pm 0.07$ \\
\hline & $2.41 \pm 0.00$ & $2.89 \pm 0.05$ & $2.83 \pm 0.09$ & $2.35 \pm 0.04$ \\
\hline \multirow{2}{*}{$\begin{array}{l}\text { Weight ratio of chlorophyll } a \text { to } \\
\text { chlorophyll } b\end{array}$} & $2.15 \pm 0.14$ & $1.95 \pm 0.07$ & $1.53 \pm 0.02$ & $1.92 \pm 0.03$ \\
\hline & $1.52 \pm 0.05$ & $1.62 \pm 0.04$ & $1.87 \pm 0.06$ & $1.80 \pm 0.10$ \\
\hline \multirow{2}{*}{$\begin{array}{l}\text { Weight ratio of chlorophylls to } \\
\text { carotenoids }\end{array}$} & $4.24 \pm 0.27$ & $4.15 \pm 0.08$ & $6.00 \pm 0.21$ & $4.69 \pm 0.09$ \\
\hline & $7.44 \pm 0.16$ & $6.86 \pm 0.21$ & $6.04 \pm 0.12$ & $5.17 \pm 0.30$ \\
\hline \multirow{2}{*}{$\begin{array}{l}\text { Proportion of chlorophylls in } \\
\text { LHC, } \%\end{array}$} & $70.15 \pm 2.93$ & $74.53 \pm 1.72$ & $86.94 \pm 0.67$ & $75.25 \pm 0.77$ \\
\hline & $87.26 \pm 1.60$ & $84.01 \pm 1.43$ & $76.62 \pm 1.56$ & $78.83 \pm 2.72$ \\
\hline
\end{tabular}

Note: upper line - aluminum acid soil, lower line-neutral soil

At the same time, our studies failed to find close links between the level of aluminum resistance of the cultivar and the degree of development of the pigment leaf complex. So, the most aluminum-resistant studied cultivar Duet Chernozemiya in the conditions of a field stress site reduced the content of both forms of chlorophyll by three times and carotenoids by $57.7 \%$. Plants of the cv. Omskaya 39 and Aktyube 19, which showed twice high depression in yield under the influence of a stressor, retained pigments to the greatest extent $-70-71 \%$ chlorophyll $a, 57-76 \%$ chlorophyll $b$ and more $80 \%$ carotenoids. According to the preservation of carotenoids (within the control values or slightly lower), both moderately resistant cv. Line 3691h, Altaiskaya 80, and cv. Aktyube 19, which is sensitive to aluminum, stood out.

Taking into account the absolute values of development of used parameters, one can note a statistically significant moderate correlation $(r=0.60)$ between the yield of the cultivar and the carotenoid content in leaves when grown on neutral soil; and the same moderate correlation $(r=0.62)$ between the yield of the cultivar and the proportion of chlorophyll in light-harvesting leaf complexes when grown on aluminum acid soil. Accordingly, these parameters for the development of the pigment leaf complex also need to be taken into account in breeding work to increase crop yield in different growing conditions.

Studies have shown the need to correct the available parameters of the wheat cultivar model in order to successfully grow it on acidic soils containing exchangeable aluminum. A comparison of the values of the observed parameters of plant development of spring soft wheat for growing on neutral and aluminum acid sod-podzolic soils is given in tab. 5 .

Table 5. Parameters of model cultivar of spring wheat in conditions of the Volga-Vyatka region.

\begin{tabular}{|l|c|c|}
\hline \multicolumn{1}{|c|}{ Parameter } & $\begin{array}{c}\text { For neutral soil } \\
\text { (according to [8] })\end{array}$ & $\begin{array}{c}\text { For aluminum } \\
\text { acid soil }\end{array}$ \\
\hline Duration of growing season, days & $67-93$ & $70-95$ \\
\hline Productivity, t/ha & $2.11-5.71$ & $1.90-2.20$ \\
\hline Amount of ear-bearing stems, pcs. & $1.0-2.5$ & $1.2-1.5$ \\
\hline Ear length, cm & $4.5-9.0$ & $5.0-5.8$ \\
\hline Number of grain per ear, pcs. & $17.0-34.5$ & $18-20$ \\
\hline Grain mass per ear, g & $0.50-1.31$ & $0.65-0.85$ \\
\hline
\end{tabular}




\begin{tabular}{|l|c|c|}
\hline Grain mass per plant, $\mathrm{g}$ & $0.50-1.72$ & $0.80-0.90$ \\
\hline Plant height, $\mathrm{cm}$ & $60-115$ & $50-70$ \\
\hline 1000-grain mass, $\mathrm{g}$ & $29.9-43.8$ & $32-36$ \\
\hline Number of leaves at flowering stage, pcs. & - & $3.0-3.6$ \\
\hline Total leaf area at flowering stage, $\mathrm{cm}^{2}$ & - & $36.3-42.6$ \\
\hline Chlorophyll $a$ content per 1 g of dry leaf matter, $\mathrm{mg}$ & - & $4.46-6.10$ \\
\hline Chlorophyll $b$ content per 1 g of dry leaf matter, mg & - & $2.32-3.12$ \\
\hline Carotenoids content per 1 g of dry leaf matter, mg & - & $1.45-2.22$ \\
\hline
\end{tabular}

The main idea of creating a model of the cultivar is the scientific justification of the morpho-physiological parameters of the plant, the level of development of which allows achieving an optimal yield in a particular growing place. The success of such approaches was demonstrated in the framework of the Drought Tolerant Maize for Africa program [13], when in just 8 years (from 2007 to 2014) more than 100 drought-resistant corn genotypes were created.

Cultivar models can be used for two main purposes, which differ significantly in practice and, accordingly, in requirements. The first goal is to use these approaches to derive new stress-tolerant cultivars (i.e., to obtain or select new initial material). To achieve this goal, it is necessary to take into account the relative levels of development of certain indicators: the proposed new cultivar should exceed the known standard cultivar in terms of the degree of manifestation of the characteristic in stressful conditions regardless of absolute level of productivity and yield. Unfortunately, most of the physiological and genetic articles related to the study of wheat resistance to aluminum acid stress focuses on the possibility of using mechanisms related to the release of organic acid anions by plant roots [14]. Wheat cultivars having genes TaALMT1 or TaMATE1B (transporters of organic acids) under conditions of acid stress are considered to be significantly more resistant than cultivars not having these genes [15]. However, only the final yield is estimated in the field conditions, without taking into account the contribution of certain elements of the yield structure of the cultivar [16]. In accordance with this, only qualitative differences in the yield of resistant and sensitive cultivars can be demonstrated. The cultivars used in our study can also be arranged according to the level of resistance expressed in terms of the degree of grain yield reduction (see tab. 1). However, unlike the works of other authors, we showed that this decrease is due to different morphological parameters. There are some articles, for example [17], which use such indicators as the degree of development of ear, the presence of ear-bearing shoots but only for a summary point score of the resistance level; the authors did not make any conclusions on the use of these indicators for breeding purposes.

The second goal is industrial production. With this goal, the level of cultivar resistance will not be decisive; the main focus should be on absolute productivity (yield), regardless of the level of stress resistance. In other words, the new cultivar can significantly reduce the level of manifestation of the characteristic (i.e., have low resistance), but at the same time, in absolute indicators of productivity under the conditions of the stress factor, significantly exceed the used zoned standard cultivar. In this case, a lot of attention should be paid to the specific values of development of the elements of yield structure. To date, the use of agronomic (the level of development of elements of plant productivity structure) and physiological (water use efficiency, chlorophyll content, photosynthesis rate, water-soluble carbohydrate content) characteristics of the cultivar has led to an overall increase in wheat grain yield when grown under favorable environmental conditions [18, 19]. Unlike such studies, we substantiated and presented the specific development values of the main parameters of yield structure that a wheat cultivar should have when grown on aluminum acid soil. No such works have been found in the literature available to us. 


\section{Conclusion}

Summing up the results of the studies, it can be postulated that under stressful conditions of acidic and aluminum acid soils, the optimal yield of soft spring wheat (at the level of about $2 \mathrm{t} / \mathrm{ha})$ is achieved by scrubby $(50-70 \mathrm{~cm})$ genotypes with low number of ear-bearing shoots (no more than 1.5 productive stems), with a relatively short ear (about $5.5 \mathrm{~cm}$ ) bearing 18-20 grains This ensures the ear productivity of about $0.75 \mathrm{~g}$ with a 1000 -grain mass of 32-36 g. To the flowering stage, such genotypes should have 3-3.5 fully developed leaves with a total area of about $40 \mathrm{~cm}^{2}$. Achieving such parameters of created wheat cultivars will solve the problem of using marginal soils for organic farming.

\section{References}

1. FAOSTAT, http:www.fao.org

2. M.A.J. Parry, M. Reynolds, M.E. Salvucci, C. Raines, P.J. Andralojc, X.G. Zhu. J. Exp. Bot., 62, 45 (2011)

3. X. Chen, D. Min, T.A. Yasir, Y.G. Hu. Field Crops Res., 137, 195 (2012)

4. M.S. Lopes, M.P. Reynolds, Y. Manes, R.P. Singh, J. Crossa, H.J. Braun. Crop Sci., 52, $1123(2012)$

5. K. Liu, H. Xu, G. Liu. Teor. Appl. Genet., 131, 839 (2018)

6. N.M. Tshikunde, J. Mashilo, H. Shimelis, A. Odindo. Front. Plant Sci., 10, 1428 (2019)

7. I.N. Shchennikova. Agric. Sci. Euro-North-East, 6(49), 9 (2015)

8. L.A. Korjakovtseva, L.V. Volkova. Agric. Sci. Euro-North-East., 6(43), 13 (2014)

9. G.A. Batalova. Oats. Technology of cultivation and breeding, 206 (2000)

10. Methods of State Varietal Testing of Agricultural Crops, 267 (1985)

11. H.K. Lichtenthaler, C. Buschmann, Current Protocols in Food Analytical Chemistry, 1(1), 4.3 .1 (2001)

12. E.M. Lisitsyn, O.S. Amunova. Russ J Genet Appl Res., 5(1), 48 (2015)

13. N. Gilbert. Nature, 513, 292 (2014)

14. P.R. Ryan, D. Dong, F. Teuber, N. Wendler, K.H. Mühling, J. Liu, M. Xu, Moreno N.S., J. You, H.-P. Maurer, et al, Front. Plant Sci., 9, 1334 (2018)

15. X. Zhang, Y. Long, J. Huang, J. Xia. Int. J. Mol. Sci., 20, 1551 (2019)

16. E.F. Wayima, A. Ligaba-Osena, K. Dagne, K. Tesfaye , E.M. Machuka, S.K. Mutiga, E. Delhaize. Agronomy, 9, 440 (2019)

17. J.G. Aguilera, P.E. Teodoro, J.P. da Silva Jr., J.F. Pereira, A.M. Zuffo, L. Consoli. Agron. J., 111, 1 (2019)

18. Y. Zhang, W. Xu, W. Wang, H. Dong, X. Qi, M. Zhao, Y. Fang, C. Gao, L. Hu. Field Crops Res., 199, 117 (2016)

19. F. Gao, D. Ma, G. Yin, A. Rasheed, Y. Dong, Y. Xiao, X. Xia, X. Wu, Z. He. Crop Sci., 57, 760 (2017) 